\title{
Human-Centered Communication Planning: A Conceptual Approach
}

\author{
Tim Schneidermeier ${ }^{1}$, Florian Maier ${ }^{2}$, and Johannes Schricker ${ }^{3}$ \\ ${ }^{1}$ Media Informatics Group, University of Regensburg, Germany \\ tim.schneidermeider@ur.de \\ ${ }^{2}$ Publicis Munich, Germany \\ florian.maier@publicis.de \\ ${ }^{3}$ Retrodigital GbR, Germany \\ jsaretrodigital.de
}

\begin{abstract}
This paper presents an interdisciplinary approach to transfer knowledge of human-centered design and usability engineering to the field of communication planning. Communication planning is a systematic process to identify target groups for specific marketing goals and when and how to reach them. We believe that by transferring methods and an overall iterative design process effectiveness and efficiency of the communication planning process as well as the overall success could be improved.
\end{abstract}

Keywords: human-centered design, communication planning.

\section{Introduction}

Many communication agencies and marketing professionals tend to test their communicational measures only at the end of their creative process right before publishing. ${ }^{1}$ If the concept fails to reach its target group or purpose the concept has to either be revised from scratch or more often due to time or financial reasons be published anyways with just a few adjustments made. The human-centered design process for interactive products on the other hand accepts failure as part of the process and focuses on testing often, repeatedly and as soon as possible. In this paper we therefore present an interdisciplinary approach to transfer knowledge of human-centered design and usability engineering to the field of communication planning. We believe that by transferring methods and know-how, effectiveness and efficiency of the planning process as well as the overall success can be optimized.

\section{Communication Planning Process}

Communication planning is a systematic process to identify target groups for specific marketing goals and when and how to reach them. Todays communication planning is

\footnotetext{
${ }^{1}$ Based on perennial practical experience with divers agencies and clients.
} 
getting more and more complex mostly due to the amount of new channels arising and the interactions in between all these channels (Suchow 2011, p. 91f). In order to manage the rising complexity, marketers are used to work with decision-based models (Bruhn 2011, p. 31ff). These models provide a step-by-step process in order to reduce the complexity and simplify the collaboration between clients and marketing professionals. Although there are several theoretical models (Maletzke 1998, p. 58f) they have to be slightly adjusted to fit the requirements of everyday work. The communication model used at advertising agencies Publicis Munich and retrodigital for example is based on a communication cycle approach developed by Bruhn and extended by adding "positioning and key messages" originating from the business-to-business (B2B) communication planning approach by Fuchs as well as "implementation" of the communication (Bruhn 2010, p. 248; Fuchs 2003, p. 19). Thus both B2B und B2C markets are covered by this approach (see Figure 1).

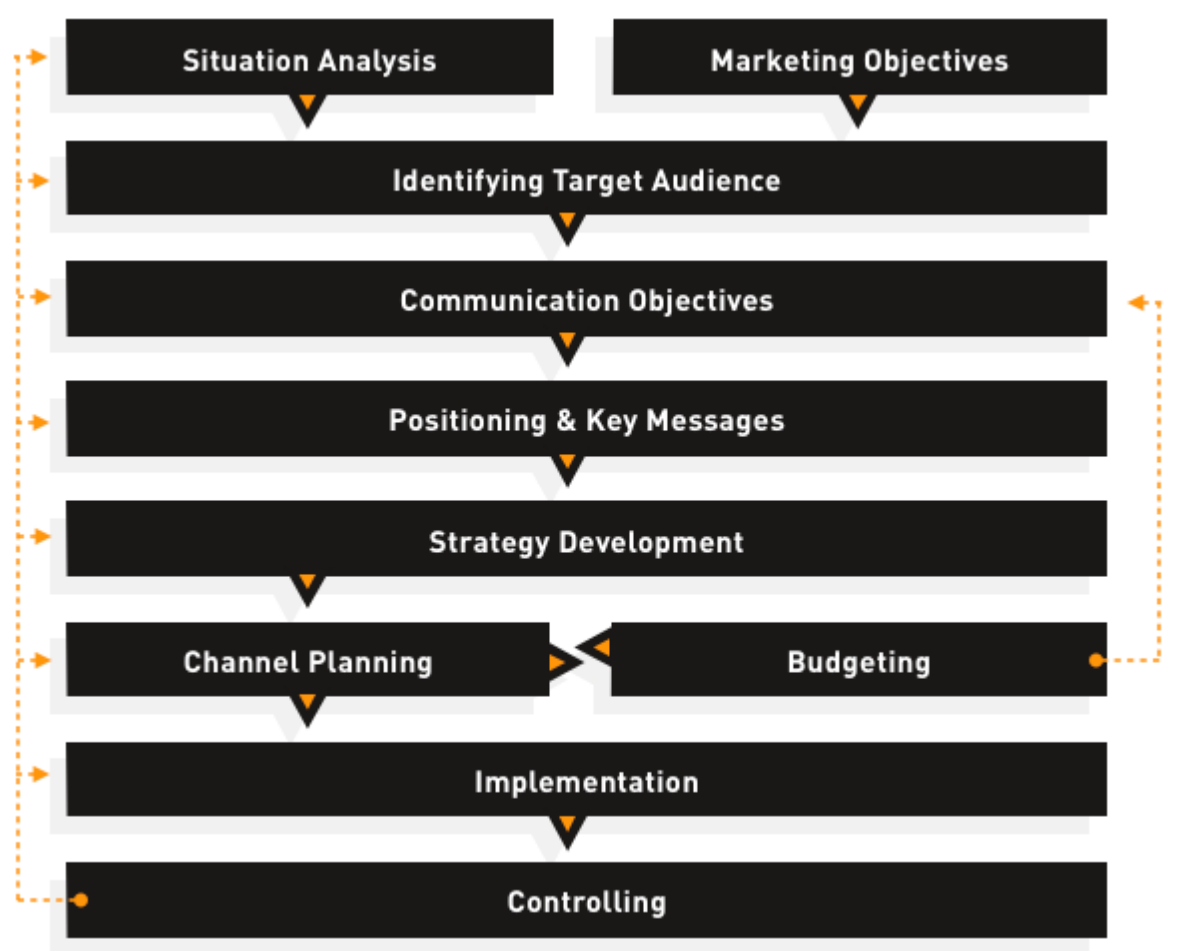

Fig. 1. Communication planning process (own illustration based on Bruhn 2010, p. 248; Fuchs 2003, p. 19)

The communication planning process includes a step-by-step procedure to define communication objectives from marketing or corporate objectives and the analysis of concrete situational internal and external factors (Bruhn 2010, p. 202f). After defining target audiences and creating a communicational positioning as well as key messages, 
the strategy development paths the way to reach the defined objectives. In order to bridge the implementation gap, a detailed channel planning as well as realistic budgeting helps to identify the right channels (Bruhn 2011, p. 31f).

Using the right channels in the right way is crucial for the success of the campaign. Methods, knowledge and experiences from the field of usability engineering and human-centered design to test and evaluate the effects of channels, key messages etc. could therefor be very helpful.

\subsection{From Communication to Usability}

The goal of advertising agencies and marketing professionals is to try to create effective messages in the best interest of their clients and choose appropriate channels in order to deliver the message to the receiver/consumer. Reaching this goal is usually based on the sender-receiver model (Shannon \& Weaver 1949; Hadwiger \& Robert 2002, p. 80ff).

By taking a closer look at this communication model (see Figure 2) it has to be noted that its original purpose was to provide a (only) technical description of how signals are encoded, transferred, decoded and received. It was explicitly not meant to describe inter-human communication. Nevertheless it found its way to practical usage as most marketers and agencies are trying to find the perfect encoding of their messages and control the noise (media planning) in order to be successful (Hadwiger \& Robert 2002, p. 80). A lot of times this results in so called push communication, based on excessive stimuli in order to exceed the receiver's perception threshold and deliver the message of the company, product or brand.

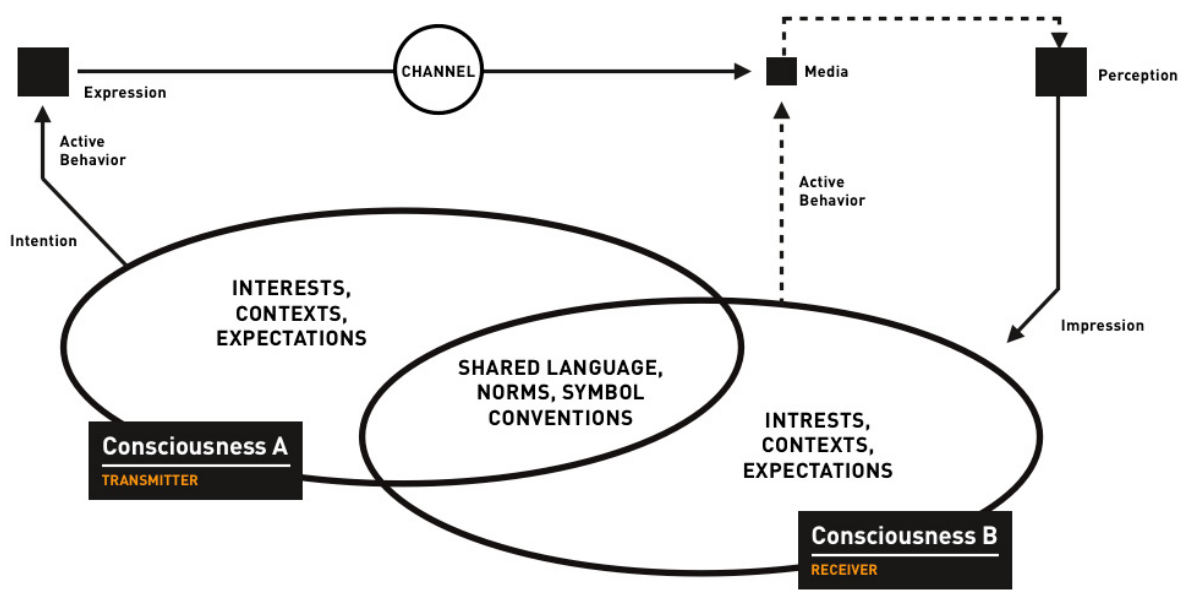

Fig. 2. Communication consciousness model (own illustration based on Hadwiger \& Robert 2002, p. 84) 
The consciousness model of communication describes an evolution of the senderreceiver model (Hadwiger \& Robert 2002, p. 84). This model extends the simplified description of decoding and integrates contexts, expectation and subjective perception of the recipient. In customer satisfaction research, the confirmation-disconfirmationparadigm explains satisfaction (or dissatisfaction) by comparing subjective expectation with subjective perception, i.e. a consumer has certain expectations, gets the message in an individual situational context and perceives the communication, media and message subjectively (Bearden \& Teal 1983, p. 21; Cadotte et al. 1987, p. 305; Churchill \& Surprenant, 1982, p. 491; Oliver, 1997, p. 99). A very similar concept is found in the user experience model, stating that the perceived quality of a product is highly dependent on the usage situation and other contextual factors. We think that by transferring human-centered design methods and including the user, i.e. the intended target group in the communication planning process the overall success of the communication measures could be improved.

\section{$3 \quad$ Human-Centered Design}

Human-centered or user-centered design is a systematic approach to design interactive products based on actual user needs and requirements. The approach is rooted in industrial design and ergonomics. The philosophy of human-centered design states that (interactive) products should fit to the user and not vice versa. It strives for optimizing the user`s experience with the product by means of what the user wants to accomplish with it and how to achieve that goal in an easy and efficient way (ISO 9241-210 2010; Saffer 2009). The design process is standardized by now within an ISO standard describing six key principles to ensure a user-centered process (ISO 9241-210):

- (a) The design is based upon an explicit understanding of users, tasks and environments.

- (b) Users are involved throughout design and development.

- (c) The design is driven and refined by user-centered evaluation.

- (d) The process is iterative.

- (e) The design addresses the whole user experience.

- (f) The design team includes multidisciplinary skills and perspectives.

\subsection{Human-Centered Design Process}

The human-centered design framework describes an iterative process to design and develop interactive products. Failure is accepted as part of the process: a first draft never results in the design solution immediately, but the road to success is affected by trying, testing, user feedback and iteration.

Although there are several specifications of the process (e.g. ISO 9241-210; Rosson \& Carroll 2002) it is essentially structured in five stages ending if the designed solution meets the user requirements (Figure 3 shows the iterative design process): 
- (1) Plan the human-centered design process

- (2) Understand and specify the context of use

- (3) Specify the user requirements

- (4) Produce design solutions to meet user requirements

- (5) Evaluate the designs against requirements

Multiple design methods provide an adequate toolbox for each stage of the process (e.g. (2) contextual inquiry, (3) task analysis, (4) sketching and prototyping, (5) user testing).

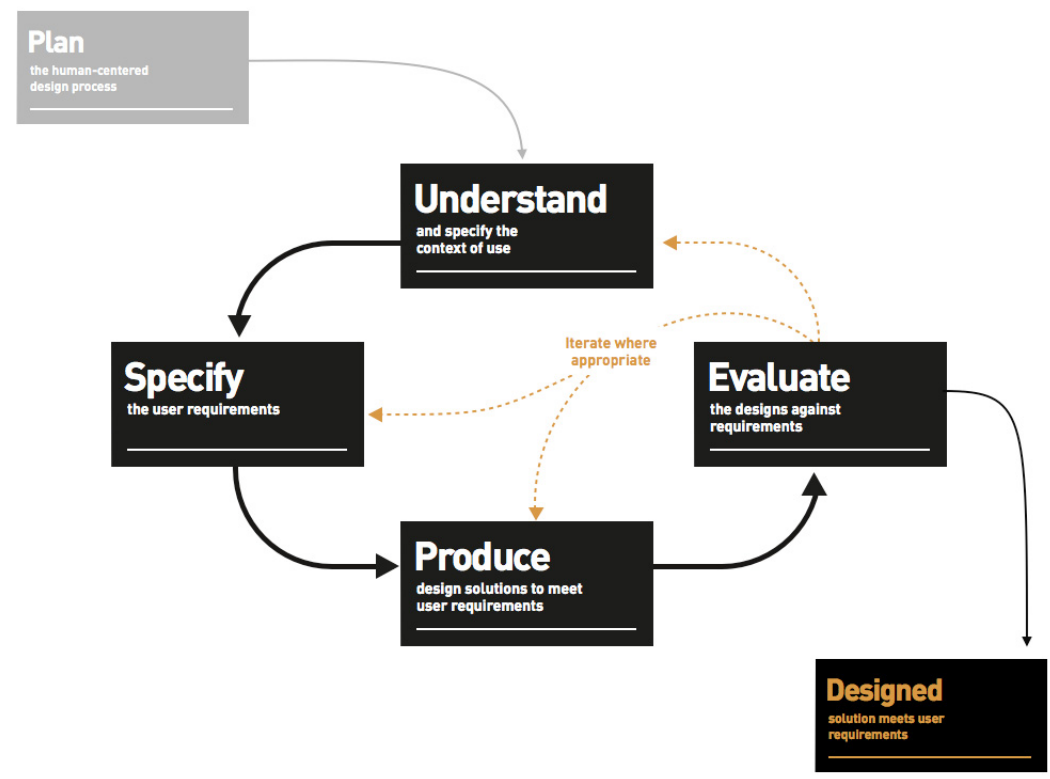

Fig. 3. Human-centered design process (own illustration based on ISO 9241-210 2010)

\subsection{Usability and User Experience}

The human-centered design process provides a framework to design interactive products that correspond to the qualities of usability and user experience (UX) ${ }^{2}$. Usability describes "the extent to which a product can be used by specified users to achieve specified goals with effectiveness, efficiency, and satisfaction in a specified context of use" (ISO 9241-11 1998, p. 4). User experience extends the concept of usability, which focuses on factors during actual use and also addresses aspects that occur before and after use. ISO 9241-210 defines user experience as "a person's perceptions and responses that result from the use and/or anticipated use of a product, system or service" (ISO 9241-210 2010, p. 7). The perceived user experience is highly influenced by the system, the user and the context of use.

2 The concept of user experience as part of an ISO standard has first been mentioned in ISO 9241-210 (ISO 9241-210 has replaced ISO 13407 in 2010). 


\section{A Conceptual Approach to Human-Centered Communication Planning}

Human-centered design and the planning of communication share some essential commonalities, e.g.:

- The resulting products of both models and their success are measured by means of effectiveness, efficiency and user satisfaction.

- Contextual factors play an important role concerning subjective expectations, subjective perception and individual satisfaction.

Therefore it seems obvious to try to transfer knowledge of the human-centered design process, usability engineering and user experience design to the field of communication planning. ${ }^{3}$ Following the human-centered design process there are numerous approved and validated methods to apply in each stage of the process. These methods serve as a systematic toolbox to support the designer in each stage (e.g. UsabilityNet 2006). We need to state, that this is a first approach rooting in experiences in practical work in the field of communication and usability engineering and has not been validated yet. ${ }^{4}$

Figure 4 shows the iterative communication planning model based on the combined approach of Bruhn and Fuchs. The idea behind the model is that all five stages of the human-centered design process are run through at the flagged stages (1-5) of the communication planning model before continuing to the next stage.

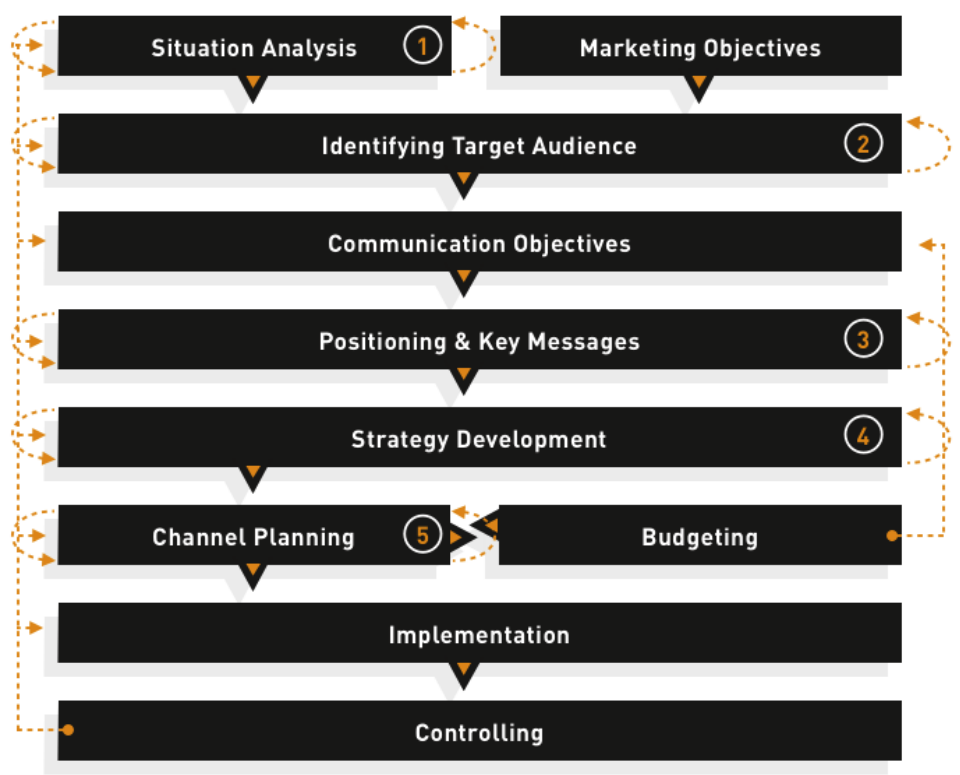

Fig. 4. Iterative communication planning model (own illustration)

\footnotetext{
${ }^{3}$ A similar approach has been taken in the field of technical communication (LaRoche \& Traynor 2010).

${ }^{4}$ A project using the approach described in this paper is planned to start in June 2013.
} 
Table 1 describes each iterative stage of the process and lists potential methods from the field of human-centered design that could be applied. ${ }^{5}$ The selection only illustrates a first abstract of possible methods, but does not claim to be complete. It is assumed that in order to successfully apply the methods in the field of communication planning they have to be slightly adapted to fit the contextual needs. ${ }^{6}$

Table 1. Iterative stages of the communication planning model and assigned human-centered design methods

\begin{tabular}{|c|c|c|}
\hline Stage & Goals & Methods \\
\hline (1) Situation Analysis & $\begin{array}{l}\text { Various analysis as a } \\
\text { basis for the communica- } \\
\text { tion project. }\end{array}$ & $\begin{array}{l}\text { logfile analysis, ben- } \\
\text { chmarking, user observa- } \\
\text { tion, interviews, focus } \\
\text { groups, eye tracking, } \\
\text { contextual inquiry, expert } \\
\text { review, competitive anal- } \\
\text { ysis }\end{array}$ \\
\hline $\begin{array}{l}\text { (2) Identifying target } \\
\text { audience }\end{array}$ & $\begin{array}{l}\text { Identifying and describ- } \\
\text { ing target audiences and } \\
\text { their situational specifica- } \\
\text { tions. }\end{array}$ & $\begin{array}{l}\text { logfile analysis, user } \\
\text { testing, expert interviews, } \\
\text { focus groups, competitive } \\
\text { analysis, surveys, contex- } \\
\text { tual inquiry }\end{array}$ \\
\hline $\begin{array}{l}\text { (3) Positioning \& key } \\
\text { messages }\end{array}$ & $\begin{array}{l}\text { Definition of the core } \\
\text { communicational posi- } \\
\text { tioning of the brand/ } \\
\text { product/ company in } \\
\text { comparison to competi- } \\
\text { tors. Derived from that, } \\
\text { key messages per au- } \\
\text { dience are formulated. } \\
\text { Each key message could } \\
\text { be tested. }\end{array}$ & $\begin{array}{l}\text { focus groups, interviews, } \\
\text { surveys, emotion track- } \\
\text { ing, card sorting, } \\
\text { SHIRA }^{7} \text {, Attrakdiff } \\
\text {, user } \\
\text { testing, heuristic walk- } \\
\text { through, prototyping }\end{array}$ \\
\hline (4) Strategy development & $\begin{array}{l}\text { A strategic approach } \\
\text { describes the way how to } \\
\text { reach the communication } \\
\text { objectives. }\end{array}$ & $\begin{array}{l}\text { brainstorming, storytel- } \\
\text { ling, expert review, focus } \\
\text { groups }\end{array}$ \\
\hline
\end{tabular}

${ }^{5}$ Please note that some of the methods presented in table 1 originate in other fields, but are commonly used in the human-centered design process.

6 This paper only presents a first conceptual approach. Further efforts will be taken to deal with the adaption of human-centered design methods.

7 cf. Hassenzahl 2001.

8 cf. Hassenzahl 2006. 
Table 2. (Continued)

\begin{tabular}{|l|l|l|}
\hline Stage & Goals & Methods \\
\hline (5) Channel planning & $\begin{array}{l}\text { Before the realization of } \\
\text { each channel, the task of } \\
\text { each channel as well as } \\
\text { the connection in between } \\
\text { all channels is described. }\end{array}$ & hrototyping, user testing, \\
At the end of this stage \\
each platform is further \\
described through plat- \\
form specific key perfor- \\
mance indicators.
\end{tabular}

\section{Conclusion}

The approach of an enhanced communication planning model presented in this paper will be implemented in the process at Publicis Munich and retrodigital. The next steps include evaluation of the process in internal use as well as in collaboration with clients. The assigned methods will be adapted, tested and refined in order to further improve the presented approach. We are looking forward to keep track of the interdisciplinary collaboration and keep working on this project.

\section{References}

1. Bearden, W.O., Teal, J.E.: Selected determinants of consumer satisfaction and complaint reports. Journal of Marketing Research 20(1), 21 (1983)

2. Bruhn, M.: Kommunikationspolitik - Systematischer Einsatz der Kommunikation für Unternehmen, 6th edn., Munich (2010)

3. Bruhn, M.: Unternehmens- und Marketingkommunikation - Handbuch für ein integriertes Kommunikationsmanagement, 2nd edn., Munich (2011)

4. Cadotte, E.R., Woodruff, R.B., Jenkins, R.L.: Expectations and norms in models of consumer satisfaction. Journal of Marketing Research 24(3), 305 (1987)

5. Churchill, G.A., Surprenant, C.: An investigation into the determinants of customer satisfaction. Journal of Marketing Research 19(11), 491 (1982)

6. Fuchs, W.: Management der Business-to-Business- Kommunikation: Instrumente Massnahmen - Fallbeispiele, Wiesbaden (2003)

7. Hadwiger, N., Robert, A.: Produkt ist Kommunikation - Integration von Branding und Usability, Bonn (2002)

8. Hassenzahl, M., Beu, A., Burmester, M.: Engineering Joy. IEEE 18(1), 70-76 (2001)

9. Hassenzahl, M.: The Thing and I: Understanding the Relationship Between User and Product. Funology: from Usability to Enjoyment, pp. 31-42. Kluwer Academic Publishers (2003)

10. Hassenzahl, M.: Hedonic, emotional and experiential perspectives on product quality. In: Ghaoui, C. (ed.) Encyclopedia of Human Computer Interaction, pp. 266-272 (2006) 
11. ISO 9241-210: Ergonomics of human-system interaction - Part 210: Human-centred design for interactive systems. Beuth, Berlin (2010)

12. LaRoche, C.S., Traynor, B.: User-centered design (UCD) and technical communication: The inevitable marriage. In: 2010 IEEE International Professional Comunication Conference, pp. 113-116. IEEE Press (2010)

13. Maier, F.: Entwicklung und Anwendung eines Kriterienkataloges für Usability und Accessibility von Content Management Systemen. In: Bayreuther Arbeitspapiere zur Wirtschaftsinformatik, Bayreuth (2005)

14. Maletzke, G.: Kommunikationswissenschaft im Überblick - Grundlagen, Probleme, Perspektiven, Opladen (1998)

15. Oliver, R.L.: Satisfaction: A behavioral perspective on the consumer, New York, p. 99 (1997)

16. Rosson, M.B., Carroll, J.M.: Usability engineering: scenario-based development of human-computer interaction Interface. Morgan Kaufmann (2002)

17. Saffer, D.: Designing for Interaction: Creating Innovative Applications and Devices. New Riders Press (2009)

18. Shannon, C.E., Weaver, W.: The Mathematical Theory of Communication, Urbana (1949)

19. Suchow, C.: Markenaufbau im Internet, Wiesbaden (2011)

20. UsabilityNet, http://www. usabilitynet.org/tools/methods.htm 